\title{
Queso gourmet desde las alturas del Valle del Mantaro-Perú
}

\author{
Luis Alberto Suárez R. \\ canio91@yahoo.es \\ Antropólogo. UNMSM \\ María Arisa Lépez Torres \\ ma_a_alt@hotmail.com \\ Estudiante de Antropología. UNMSM
}

\section{Introducción}

En el Perú la agroindustria tiene que convivir con la heterogeneidad de la agricultura de pequeña escala comercial, que en buena cuenta es resultado de una serie de transformaciones pos reforma agraria, la misma que obedece a una lógica propia. La agroindustria ha tenido un mayor impulso durante este último quinquenio, gracias a la creciente demanda del mercado internacional, especialmente por productos orgánicos, como las alcachofas, la papikra, el palmito, el café, el banano, y el cacao, entre otros. Entre el 2000 y el 2007 se produjo un crecimiento sostenido de exportaciones de productos orgánicos, en el 2001 se vendieron productos de agroexportación al exterior por US\$ 645 millones, y al cierre del 2006 se logró vender productos que representaron US\$ 1.786 millones. Un caso especial lo representa el espárrago, pues el $95 \%$ de la producción total se comercializa en el extranjero, en el 2006 los envíos al exterior sumaron US\$ 187 millones de dólares.

Desde su orilla, elEstado estimula la efervescencia del crecimiento del sector agroindustrial, mientras que en el campo los pequeños agricultores viven una serie de consecuencias producto de las variaciones del cambio climático, las temporadas de sequía, y las variaciones del precio de sus productos en mercados regionales y locales. En medio de este contexto, la agroindustria estimula una movilidad creciente de fuerza de trabajo re-construyendo un flujo de mano de obra constituido fundamentalmente por jóvenes y adultos, que en función a la suerte de estas industrias se emplean de manera temporal, dibujando un escenario de inestabilidad y precariedad. Según la OIT, el $58 \%$ de la mano de obra remunerada del sector agrario está en la Sierra, el $27 \%$ en la Costa y el $15 \%$ restante en la Selva, y se estima que hay 250000 personas empleadas en la agroexportación a todos los mercados, incluyendo EE. UU. Por contraste, las estadísticas señalan que la agricultura ha aportado menos del $10 \%$ del PIB en los últimos años, a pesar de ello, el $30 \%$ de la población peruana depende de este sector, que además emplea al $35 \%$ de la población económicamente activa. 


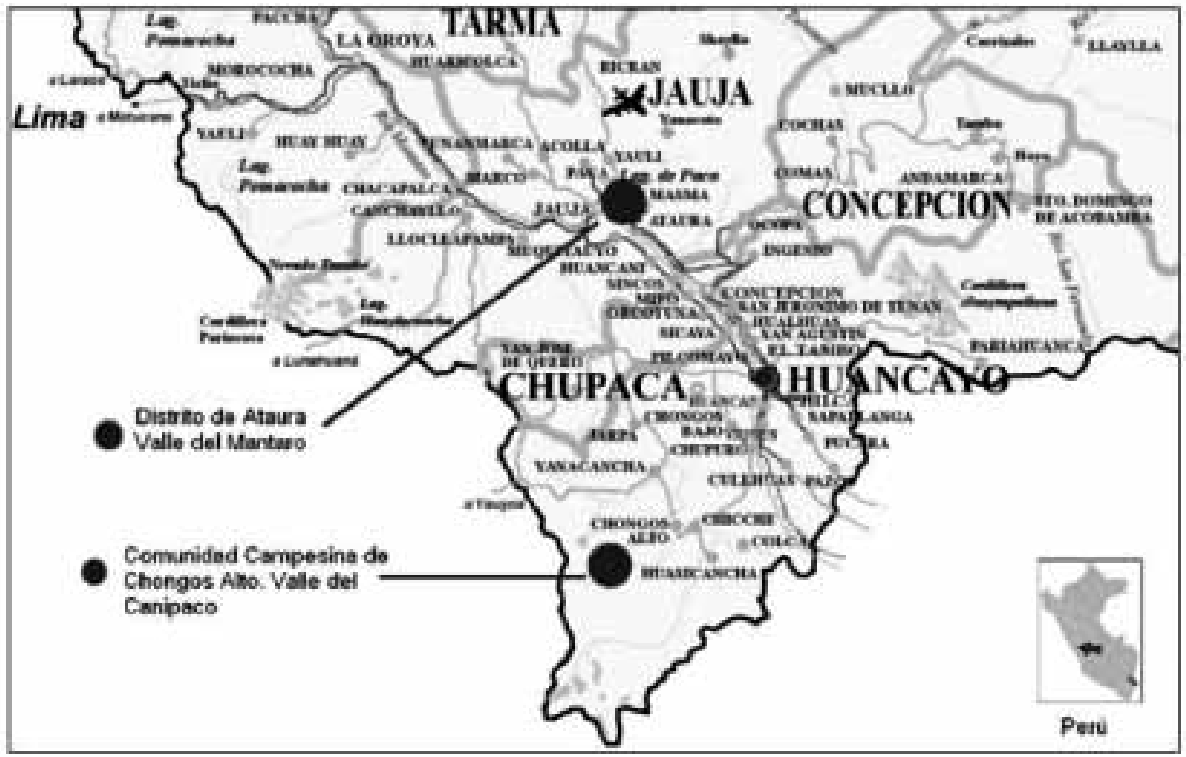

Mapa del departamento de Junín. Area del estudio.

El Estado Peruano, a través del Ministerio de Comercio Exterior y Turismo (MINCETUR), señala que el sector agroindustrial ha generado unos 400 mil puestos de trabajo, de los cuales un $70 \%$ corresponde a mujeres y que por cada puesto de trabajo directo en el sector agrícola se generan 2,1 empleos indirectos. Por su lado, los portavoces del Estado insisten en frases retóricas: "la agro exportación como alternativa de desarrollo", o "la agroexportación no tradicional como opción de desarrollo"; sin embargo, las hechos no son del todo alentadores; por ejemplo, las mujeres del sector agroexportador son testigos privilegiados y víctimas de las políticas laborales de algunas empresas y la desprotección del Estado. Tales industrias despiden mujeres trabajadoras que se embarazan arguyendo que retrasan la producción, a otras se les niega el descanso pre y posnatal, entre otros derechos. La razón más usada por parte de las empresas agroexportadoras para actuar así, es la baja productividad que éstas en su estado originarían.

Por otra parte, muchos de los campesinos que en promedio poseen menos de 1 hectárea, son conminados a re-orientar sus productos en función a la demanda de industrias de agro-exportación, que en el campo son proyectadas como la "oportunidad de oro". Esto ha provocado que la superficie sembrada con cultivos agroindustriales haya aumentado en los últimos años, a aproximadamente 70,000 hectáreas en la costa. Todos esos datos constituyen algunos aspectos de un cuadro general sobre la agroindustria. Pero es necesario ir de lo general a lo particular, en ese sentido, en las siguiente líneas examinaremos la industria de agroalimentos en la sierra central del Perú, pues, ofrece un contexto que permite observar compleja relación entre ciudades y espacios rurales como Jauja, Huancayo, Tarma, Chanchamayo y Satipo, las cuales articuladas constituyen importantes corredores económicos, que van desde la "ceja de selva" (pie de monte), pasando por las ciudades alto-andinas, hasta llegar a la capital (Lima). Este corredor articula la diversidad agroecológica, la riqueza de recursos naturales, y una poderosa agroindustria, que se encadenan con mercados regionales, y demandas globales, dibujando intensas conexiones. Por lo tanto, el escenario de nuestro examen es la sierra central del Perú, y exploraremos la articulación de las comunidades campesinas a la agroindustria en dos valles contiguos: el 
Valle del Mantaro y en el Valle Canipaco, donde en ambos tenemos una fuerte presencia de pequeña agricultura, con matices diferentes en las formas de organización social y formas de emprendimiento local.

En este contexto hemos elegido al "distrito de Ataura" (Valle del Mantaro) y a la "comunidad Campesina de Chongos Altos", (Valle Canipaco) dónde la Empresa Láctea Andina S.A., y el programa estatal "Sierra Exportadora", han firmado un convenio para producción y exportación de queso gourmet de oveja, al mercado estadounidense, con la participación de comunidades campesinas de la región Junín. En ese sentido, ambas instituciones públicas y privadas, se unen con el objetivo de abastecer al $0.5 \%$ del mercado minorista de quesos gourmet de oveja a Estados Unidos, cuyo valor exportable es de 15 millones de dólares anuales, sobre una demanda total estimada en 3 mil millones de dólares por año, por lo que se pretende habilitar 1000 hectáreas de pastos cultivados en 10 módulos ${ }^{1}$ de 1500 ovejas lecheras, integrando a las comunidades de zonas alto andinas y de extrema pobreza de la cuenca del río Canipaco y del Valle del río Mantaro, a fin de articularse con el mercado internacional. Actualmente, Láctea Andina S.A. firmó un convenio de usufructúo de tierras con la comunidad de Chongos Alto en Junín. Este proyecto empresarial se ha encadenado a la empresa Agromantaro S.A para proveer de brácteas de alcachofa -que son órganos de la planta próximos a las flores, que no constituyen precisamente hojas, y se encargan de proteger a la planta- para la alimentación de las ovejas productoras de leche.

Las comunidades campesinas y las zonas rurales no son entidades sociales vaciadas de historia, ni aisladas de procesos complejos producidos a escala nacional y regional. Por lo tanto, todo acercamiento al espacio rural supone un ejercicio de historicidad que permita comprender la compleja trama social, cultural y económica; sin dejar de lado los procesos contemporáneos que enlazan lo local con lo global

Desde una perspectiva histórica, podemos señalar que a principios del siglo XX, la estructura social del Valle del Mantaro (Región de Junín-Perú) respondió al sistema de dominación tradicional andina, en este contexto Jauja gozaba de una posición hegemónica a manos de un pequeño grupo dominante (con un sistema de autoridades locales y regionales). Sin embargo, a mitad del siglo XX, con la minería, el sistema de enganche en las comunidades campesinas que ofrecía anticipos de pagos ínfimos a los campesinos por un trabajo que no era proporcional a la explotación por parte de los grandes terratenientes; el auge del comercio, la emergencia de nuevos grupos sociales con poder económico, nuevas rutas de transporte, y la urbanización (producto de la migración tanto dentro como fuera del Valle), provocaron el ocaso de Jauja, produciendo un cambio sustantivo en la estructura social de las sociedades rurales aledañas. Es así, que buena parte de la población marginada de los centros de dominación local tradicional se constituyó en un elevado contingente que alternó el trabajo en las minas y en el campo, experimentando nuevas formas de vida y añadiendo a su capacidad cognoscitiva nuevas percepciones de la realidad (Alberti:1974). Estos campesinos, regresaron a sus comunidades de origen y fueron organizadores de los movimientos de autonomía comunal que socavó las bases del poder a la élite tradicional (Alberti:1974). El ocaso de Jauja provocó el nacimiento y el fortalecimiento de la ciudad de Huancayo como nueva centralidad económica, política y social, con un entorno rural permeable a la dinámica y exigencias del mercado regional.

Este pasado constituye el entramado social y cultural en el cual se forjan una serie de capacidades locales que se entrelazan con posibilidades reales de emprendimiento

1 Según, los datos cada uno de los módulos requiere de 500 mil dólares, de los cuales 300 mil dólares son para la compra de las borregas, 100 mil dólares para la siembra de pasto e instalación de cercos para el pastoreo, y 100 mil dólares para la construcción de corrales, sala de ordeño y capital de trabajo para iniciar la operación 
social y económico, en este caso, notamos un pasado cultural muy importante entre las comunidades del Valle del Mantaro; sin embargo, la minería que en el pasado les permitió proyectarse hacia el futuro, hoy se constituye en uno de los principales escollos; pues, los efectos de la contaminación por parte de las empresas mineras en el Valle del Mantaro, representa el principal obstáculo para el desarrollo de actividades agrícolas y pecuarias en estas comunidades. En el caso de Ataura, a inicios de esta década se instaló una planta procesadora de alimentos que permitía la transformación de la materia prima, y darle al mismo tiempo el "valor agregado", esto estimuló un intenso flujo de fuerza de mano de obra semicalificada, además de la emergencia de servicios complementario propios de toda industria.

Es de esta manera que la dinámica de la industria provocó que los agricultores cambiaran sus habituales cultivos por granos, pero tras un análisis más detallado de las condiciones de la empresa procesadora, por parte de la contraparte norteamericana, detectaron que el agua proveniente del río Mantaro - Cuenca a la que pertenece la comunidad- estaba contaminada debido a la incesante actividad de los centros metalúrgicos aledaños, en ese mismo instante el futuro de la empresa procesadora fue sellada, y quebró inevitablemente, los campesinos se quedaron con sus cosechas y sufrieron los embates del bajo precio; posteriormente otra empresa se aventuró al reto de procesar alcachofa, de esta manera, alentaron a los campesinos a reorientar sus cultivos; la mayoría de los ataurinos cultivaron la alcachofa hasta que pocos meses después un Ministro de Estado inauguró la planta de procesamiento con la que se avizoraba un futuro promisorio; no obstante la historia se repitió y las alcachofas fruto del Mantaro, no pasaron los exigente controles de calidad. No obstante, las comunidades de los alrededores poseen mejores condiciones para el desarrollo de la agricultura.

Por otro lado, el Valle Canipaco se encuentra muy próximo a la ciudad de Huancayo, actual centro hegemónico de la economía regional; este valle posee un entramado de prácticas culturales y sociales, que predisponen e influencian fuertemente en la vinculación con proyectos agroindustriales actual. En ese sentido, la Comunidad de Chongos Altos ofrece un contexto particular, y es una de las comunidades que más rápidamente se incorporado al "círculo virtuoso" de la empresa Láctea Andina y al gran proyecto del queso gourmet.

\section{Láctea andina y el "ciclo virtuoso" de la agroindustria: cooperación internacional, estado y recursos locales}

Láctea Andina es una empresa peruana, anclada en el norte del país, que pretende expandirse en la sierra centro del Perú. Hoy, constituye un proyecto de exportación de quesos de oveja a Estados Unidos de Norteamérica. Según las cifras, en este país, el consumo per cápita de quesos se estima en 35 libras al año, por otra parte, el mercado minorista de quesos gourmet es de US\$ 3 billones al año. El objetivo de Láctea Andina, es lograr abastecer al $0.5 \%$ del mercado de quesos gourmet, estimando una exportación anual de US\$ 15,000,000. Para lograr esta meta, Láctea Andina se está articulando con la ganadería ovejera en la sierra central, específicamente con las comunidades de la Cuenca del Canipaco (Jauja - Junín). En términos generales, el proyecto consiste en la crianza de ovinos lecheros para la producción de quesos, los cuales se realizarán en la Planta Piloto de elaboración de quesos de ovino, ubicada en el distrito de Ataura (Jauja - Junín); esta planta contará con equipos provenientes de Argentina; y se construirá la infraestructura productiva y de ordeño. El alimento de las ovejas proviene de pastos cultivados (donde se crían las ovejas lecheras) en el terreno de las comunidades campesinas beneficiarias. 
En este sentido, es vital la articulación de las comunidades campesinas involucradas, y se espera contar con 10 módulos de 1500 ovejas cada uno, con una inversión total de cinco millones de dólares, de los cuales ya Sierra Exportadora articuló a LÁCTEA S.A. para que COFIDE financie en una primera etapa la suma de un millón de dólares. Estos módulos para 1500 ovejas son cedidos por un periodo de seis (06) años a favor de LÁCTEA ANDINA S.A., el área necesaria para realizar todas las actividades, desde la crianza de las ovejas, el crecimiento de pasto, el ordeño, entre otros aspectos. Al séptimo ( $7 \mathrm{mo}$ ) año de operación, LÁCTEA ANDINA S.A. devolverá los terrenos a los comuneros con las mejoras desarrolladas (animales, infraestructura productiva, pastos instalados, etc.).

La propuesta, que animó a las comunidades involucradas, consiste en que las mismas comunidades tomen la batuta de la administración del negocio de producción de leche de ovino con todo el "know how" adquirido durante los primeros años de operación del proyecto; según Láctea Andina, estas comunidades tendrán un mercado seguro para la venta de leche durante casi quince (15) años. Es necesario señalar, que en el proceso, la invocación tecnológica es indispensable; puesto que las ovejas que participan del proyecto son producto del cruce entre ovejas de pelo corto con gran capacidad reproductora, y ovejas con gran capacidad lechera. En ese sentido, se ha logrado transferir los primeros 150 embriones congelados de ovinos lecheros, los cuales han sido importados desde Australia en el marco del proyecto de ovejas queseras gourmet de ovino para exportación. Esto es un trabajo conjunto entre las comunidades campesinas, quienes cuidarán de estas ovejas, la empresa privada y el Estado ${ }^{2}$ que asegura la participación de equipos de alta tecnología. En suma, se transfirieron los primeros embriones de alta calidad genética de la raza lechera Frison Alemán (Australia) a 50 vientres de raza Black Belly (raza prolífica).

En este proyecto existe un encadenamiento entre los módulos de las ovejas lecheras y las alcachofas, que representan un extraordinario boom dentro de las agroexportaciones. En la actualidad, Junín, es uno de los departamento de mayor producción de alcachofas, el subproducto de las alcachofas se convertiría en el alimento de más de 1500 ovinos lecheros.

Láctea Andina considera a Junín una región con un importante potencial, y espera que se convierta en la "Primera Cuenca Lechera de Ovinos de Sudamérica", pues cuenta con excelentes pastos, y una larga tradición de crianza de ovejas, $\mathrm{y}$ un conocimiento local dirigido especialmente a la crianza y cuidado de ovejas, tanto para la carne como para la lana. En Junín existe el 10\% de la población ovina del Perú, es decir, 1'250,000 cabezas, y además, 1'146,000 Hectáreas de pastos naturales en sierra y 18000 hectáreas de pastos cultivados donde se desarrolla ganadería. Ahora, estos ovinos serán reemplazados por ovinos lecheros, pero con el agregado, es que son ovejas producto del cruce entre dos razas, esto es algo nuevo con lo que tendrán que lidiar los comuneros y pastores.

\section{Láctea andina, y estrategias de producción}

El plan de Láctea Andina, señala que la empresa será la operadora de cada módulo por un periodo suficiente y necesario para recuperar la inversión y cubrir los costos del crédito. Según este plan entre 5 y 6 años, posteriormente, pasa a mando de las comunidades, siempre y cuando el personal sea rigurosamente entrenado, para lograr la "rentabilidad probada"; además, la empresa asegura un encadenamiento durante más de 10 años.

2 Asimismo, la participación de los involucrados en el proyecto se formalizará mediante acuerdos interinstitucionales, por lo que ya se suscribió un convenio entre Sierra Exportadora y LÁCTEA ANDINA S.A. Actualmente, está en elaboración el acuerdo tripartito entre Sierra Exportadora, LÁCTEA ANDINA S.A. y las Comunidades Campesinas beneficiarias. 


\section{Participación de la comunidad}

Las comunidades movilizan y entregan un terreno con las condiciones suficientes para cultivar y cosechar pasto, que sirva como forraje para las ovejas; además de agua permanente, y el área para desarrollar la infraestructura orientada al manejo y ordeño de los animales. Por otra parte, se ha asegurado la contratación de personal para las diferentes labores, además existe un compromiso por parte de la empresa de promover capacidades y transferir información. Es importante, considerar que esta empresa necesita contar con una fuerza de trabajo importante, pues, es necesario acopiar alrededor de $12500 \mathrm{~kg}$ de leche de ovinos diariamente para abastecer con quesos el mercado objetivo, esto implicaría la crianza de 37500 ovinos dedicados a esta actividad y el desarrollo de 1000 hectáreas de pastos cultivados.

Cada módulo requiere una inversión estimada de US\$ 500,000, siendo las partidas principales: US\$ 300,000 para adquisición de 1500 borregas lecheras, US\$100,000 para desarrollo de 100 hectáreas de pastos cultivados, cercos eléctricos e infraestructura de pastoreo y US\$ 100,000 para infraestructura de ordeño y capital de trabajo hasta iniciar la venta de leche. Láctea para crear esta espiral de desarrollo podrá financiar al mismo tiempo las primeras 1500 ovejas lecheras. Consideramos una espiral de desarrollo, puesto que este primer módulo en 12 meses será capaz de vender a los siguientes módulos 500 ovinos lecheros anualmente y así sucesivamente los siguientes, generando capacidad de pago de deuda rápidamente mientras consolida su producción de leche.

La empresa ha iniciado la producción de quesos con leche de oveja para el Mercado Nacional y está en permanente búsqueda de nuevos clientes, capacitación y desarrollo de nuevos productos para el mercado de exportación.

Según las notas de Láctea Andina, la empresa posee más de 5000 ovinos, y ha iniciando los cruces con razas lecheras desde hace un año para disponer de borregas lecheras de alta calidad genética, estando en proceso la importación de semen de ovinos Frison Alemán.

\section{Láctea Andina y las comunidades campesinas}

Fue la misma empresa Láctea Andina, la que fue hacer el contacto con diferentes comunidades. De modo que recorrieron muchas comunidades del Valle Canipaco, y muchas de las comunidades respondieron que no les interesaban porque no poseían el terreno suficiente para brindar a la empresa en concesión, pero además, las otras comunidades eran ya proveedores de leche para otras empresas; en ese sentido, desestimaron la propuesta de Láctea Andina. Al llegar a la comunidad de Chongos Alto, expusieron a las autoridades locales, quienes al mismo tiempo invitaron a una reunión, donde participaron todos los comuneros; por su parte, Láctea Andina expuso los beneficios, así como los compromisos; en esta reunión los comuneros deliberaron sobre los beneficios, y se creó expectativa al respecto de las capacitaciones, la posibilidades de empleo, y fundamentalmente, en torno a la formalidad jurídica sobre la cual se dejaría en concesión el terreno que necesitaba Láctea Andina para operar. En este caso, hubo una excelente convergencia de interesesy trayectorias, que hacen posible pensar en la propuesta de Láctea Andina, en una oportunidad. De este modo, en enero del 2008 se inició la construcción del primer módulo piloto en Chongos Alto, se espera la crianza de mil 500 ovinos lecheros. En la actualidad, están apoyando en la organización de las comunidades comprometidas como Chongos Alto y Paccha, para reforzar la presencia de la empresa Láctea Andina; además están trabajando para sensibilizar a otras comunidades: Llamapsillón, Vista Alegre, Apata y San Lorenzo, a fin de incorporarlas y lograr contar con las 10 comunidades campesinas que abarcará el proyecto. 


\section{Cooperación Internacional, Estado y empresa privada}

En el caso de este proyecto, la cooperación internacional también interviene a través USAID quien ha facilitado los contactos para obtener el protocolo de sanidad, esto teóricamente permite que los quesos gourmet sean incorporados en el mercado americano. Según Láctea Andina, la intervención de USAID ha sido decisiva en la declaración de poder exportar quesos de oveja en pequeñas cantidades, posteriormente ellos podrán evaluar cuáles serán los pasos siguientes a efectuar. Por otra parte, en este proyecto concurren actores como el Centro de Servicios Económicos (CSE) Huancayo ${ }^{3}$ del Proyecto de Reducción y Alivio a la Pobreza (PRA-USAID), quienes han asumido la asistencia técnica especializada a través de la contratación de un experto en el desarrollo ovino en la sierra. Por su parte, Centro de Servicios Económicos (CSE) Huancayo ha conversado con pastores del Valle del Mantaro para que establezcan módulos pequeños de 50 ovinos, a fin de convertirse en proveedores de leche de oveja, para así abastecer directamente a la planta instalada en Ataura. Incluso, han propuesto a la Minera Sinaycocha (Comas, Junín) la posibilidad de promover la crianza de ovinos en la Comunidad Campesina de Canchapalca. Asimismo, el Ministro de Agricultura ejecutó un curso sobre "Mejoramiento Genético" durante abril, en la comunidad campesina de Chongos Altos. Finalmente, el Programa Nacional de Manejo de Cuencas Hidrográficas (Pronamachcs) se encargará de instalar y sembrar pastos cultivados, implementar infraestructura productiva (obras de riego, cobertizos y almacenes), reforestación y asistencia técnica.

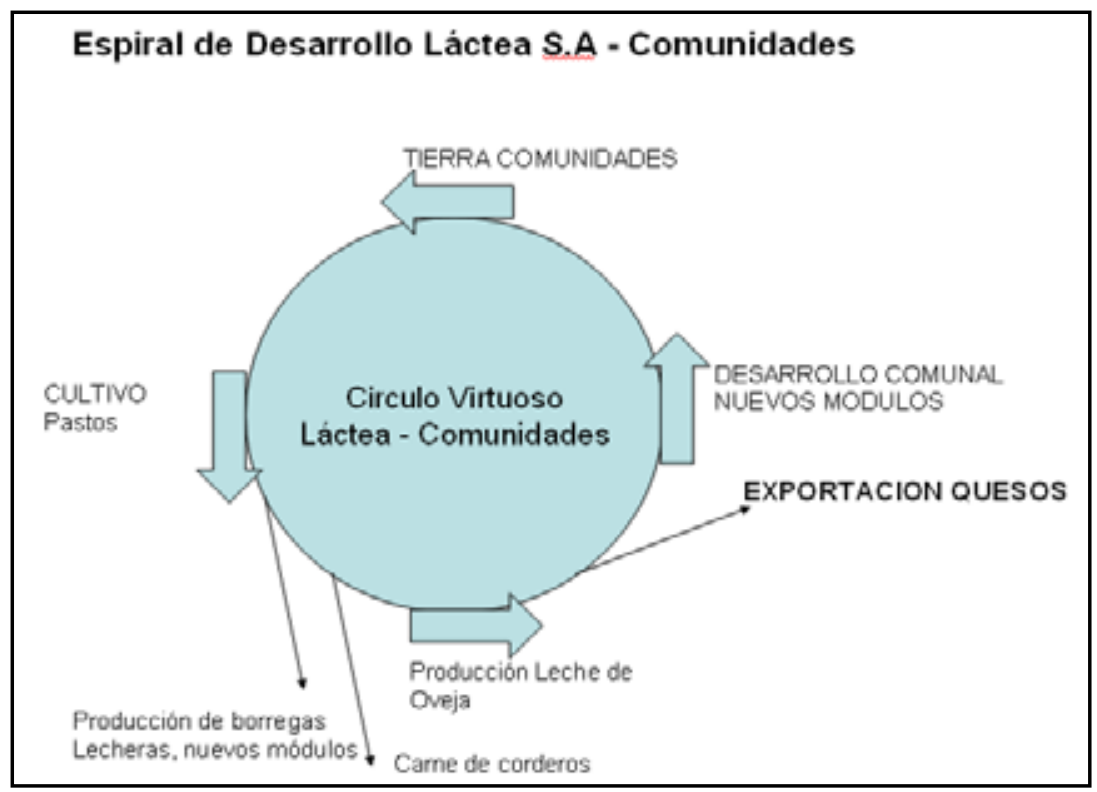

3 Centro de Servicios Económicos (CSE) Huancayo del Proyecto PRA inició los primeros contactos comerciales con importantes empresas agroexportadoras del norte, las cuales comenzaron a tener una gran demanda de conservas de alcachofa proveniente de sus clientes compradores de espárrago, razón por la cual mostraron un gran interés en el ofrecimiento del CSE Huancayo de abastecerse de la producción de alcachofa del Valle del Mantaro. Siendo esto así, se empezó la tarea de organizar, en el Valle del Mantaro, una oferta suficiente con la calidad y oportunidad que exigía el mercado. 


\section{La agroindustria y su incrustamiento en las estructuras cognitivas, y tramas socio-culturales en los andes centrales}

Focalizaremos nuestra exploración en dos localidades ubicadas en cuencas próximas, ambas pertenecientes a la provincia de Junín. El análisis empírico en el que se basan estos estudios proviene de información recogida en la localidad de Ataura (3200 msnm), perteneciente al Valle del río Mantaro y en la localidad de Chongos Altos ${ }^{4}$ (3544 msnm), ubicada en el Valle del río Canipaco, ambas ubicadas en el departamento de Junín. Ataura se encuentra rodeado por un conjunto de comunidades campesinas, su singular historia contrasta con el desarrollo paralelo de las comunidades aledañas ${ }^{5}$, las cuales en el siglo XX se fortalecieron, expandiendo su territorio y debilitando a Ataura, el cual, por muchos años mantuvo una estrecha relación con Jauja, centro de poder mestizo en el Valle, y antiguo centro de poder de los Xauxa. Actualmente, Ataura es considerado uno de los distritos más pequeño del Perú, debido a la pérdida de su territorio. A pesar de tener prácticas propias de una organización comunal (faenas, asambleas, sistemas de cargos, junta de regantes, etc.), Ataura nunca logró la consolidación de un sistema de administración comunal. Por contraste Chongos Altos, en el Valle del Canipaco, es una comunidad campesina muy fuerte, con un pasado cultural teñido por la etnia de los Wanka, en esta zona predominaron desde comienzos del siglo $\mathrm{XX}$, las haciendas y el ganado vacuno, en este caso, la población se articuló al sistema de haciendas ${ }^{6}$.

\section{Ataura}

El distrito de Ataura está caracterizado por la preeminencia de redes familiares en su organización, ya que tradicionalmente era en función a éstas que se organizaba la política. En la actualidad debido a constantes conflictos de tierras y otros avatares, Ataura se ha convertido en el distrito más pequeño del país, razón por la cual, no es posible que se organice bajo la forma jurídica de comunidad campesina. Sin embargo, pese a todas estas contingencias y distintos acontecimientos, los pobladores de Ataura aún reconocen una división espacial del pequeño territorio Ataurino en tres cuarteles ${ }^{7}$. Desde la década de 1930, Ataura ha sufrido drásticos cambios debido a distintos factores como la migración con la que se inicia la desestructuración del poder comunal, desestructuración que se acelera en la década de 1980, debido a la acción del grupo terrorista Sendero Luminoso; tal como lo relata un ilustre poblador del distrito de Ataura:

"Las personas ahora tienen miedo de ir a las sesiones, la vida institucional se ha perdido y la juventud ya no se interesa por el distrito". ${ }^{8}$

4 Este distrito limita con la provincia de Chupaca y los distritos de Chicche, Huasicancha y Chacapampa. Posee una ubicación estratégica porque a la vez limita con los departamentos de Huancavelica y Lima, capital del Perú.

5 Los comuneros de Muquiyauyo sin ningun apoyo del gobierno habian construído una de las primeras o quizas la primera hidroelèctrica en el Perú en 1918

6 Incluso tenemos referencias históricas que señalan que en el año 1657, el Curaca de Hanan Huanca, Don Carlos Apoalaya, tenía en la estancia Ingahuasi 26000 cabezas de ovino castilla, en Huayucachi 300 ovejas, en Huancayo 350 ovejas de castilla (según almanaque de Junín 2001-2002).

7 Vista Alegre, Yanasiugo, Hasha, que antaño fuera el cuartel que se caracterizaba por ser el más organizado, donde cada uno de estos está conformado por dos barrio. Estos cuarteles poseen un presidente, elegido en base a méritos personales y comportamiento ejemplar por medio de elecciones democráticas. Este se encarga de coordinar algunas actividades, que constituyen una reminiscencia de la antigua organización comunal, tales como asambleas y trabajos comunitarios (limpieza de acequias y canales de regadío). En la actualidad, la organización de estas actividades se ha debilitado considerablemente, sin embargo, continúa como una expectativa latente.

8 Conversación con Efraín Miranda Suárez, presidente de uno de los cuarteles en los que se divide Ataura y catedrático de la Universidad Nacional del Centro del Perú. 
Sendero Luminoso pretendía conformar grupos de apoyo, sin embargo después de un atentado al municipio Ataurino donde se quemó una parte de las instalaciones, sus pretensiones no tuvieron un eco en la comunidad que se encontraba en la zozobra debido a lo que venía sucediendo en comunidades aledañas como Chongos Altos, donde los ataques de este grupo eran brutales.

En la actualidad, figura como uno de los territorios que se encuentra más empoderado del Valle del río Mantaro, debido a su ubicación estratégica al lado de la carretera, por la que se conectan las poderosas localidades de Huancayo y Jauja, concepción que dista mucho de la realidad que se vive en el distrito, debido a que a pesar de ser punto de conexión entre estas importantes localidades, no cuenta con servicios básicos permanentes; sin embargo su situación la ha ubicado bajo la mirada de empresas agroindustriales y grandes transnacionales, las que han apostado por potencialidades de los pobladores, que representarían el progreso de la localidad, presentándoles una visión innovadora a la tradicional concepción de desarrollo de los Ataurinos:

"¿Qué se está entendiendo por desarrollo? -La gente cree que desarrollo es sembrar fierro, cemento y ladrillo, acá no ven nada más que eso." 9

La empresa Agroindustrial TALSA, del grupo trujillano Rocío, apostó por la instalación de una moderna planta procesadora de alcachofas en Ataura, en la que invirtieron solamente en la implementación de las instalaciones alrededor de 300000 dólares. Todo este boom generó grandes expectativas en los pobladores que optaron por cambiar sus cultivos tradicionales, cultivos por los que en el mercado obtenían una cantidad ínfima de dinero, que difícilmente lograba cubrir el costo de los fertilizantes, que en la última década han triplicado sus precios y sin los cuales la tierra no brinda frutos debido a su incontenible erosión y debilitamiento. El impacto que generó la instalación de la planta procesadora en Ataura se hizo patente el "Plan de Desarrollo Estratégico de Ataura", que impuso en su visión al año 2013 a este distrito como uno de los principales exportadores de la alcachofa.

TALSA representaba una alternativa prometedora para la comunidad, mas no debemos de olvidar un detalle importante. Ataura, como ya lo hemos mencionado anteriormente se ubica en el Valle del Mantaro, territorio rico en minerales y ecosistemas diversos, pero donde la contaminación alcanza niveles escandalosos. La Oroya - uno de los principales centro polimetálicos del Perú-, figura como uno de los lugares más contaminados del planeta, todo esto como consecuencia de la actividad minera, los relaves y las aguas que no son tratadas adecuadamente y que se vierten en el cauce del río Mantaro; todo esto sumado a los malos hábitos de los pobladores que dañan el medio ambiente, representan los elementos que destruyeron las expectativas generadas por TALSA.

El uso del agua marcó el destino de Ataura como productor de Alcachofas. A pocos meses de iniciadas las actividades de la planta, se enrumbaron algunos contenedores de alcachofas hacia Europa, a los que se les realizaron las pruebas toxicológicas correspondientes; el resultado de estas pruebas reveló una alta concentración de minerales pesados en los vegetales. Ante esta alarmante situación, se intentó falsear las pruebas obtenidas en los laboratorios para evitar grandes pérdidas económicas a la empresa, sin embargo, una delegación Europea se hizo presente en las instalaciones de la planta, donde la contaminación de los productos se convirtió en inocultable. Ante esta situación, los administradores declararon en quiebra económica a la empresa para evitar las represalias legales. Toda esta situación generó un gran desconcierto en los pobladores, que vieron el suceso como un eslabón más en la cadena de proyectos truncos de su localidad; sin embargo, esto no mermó del todo la confianza y la capacidad de apostar en proyectos alternativos de los pobladores de Ataura.

9 Efraín Miranda Suárez. 


\section{Chongos Altos}

En el valle del Canipaco una de las comunidades que mejor ha logrado articularse con el propósito de Láctea Andina, ha sido la comunidad de Chongos Altos. ${ }^{10}$ Hoy en día, esta comunidad ha sabido negociar y movilizar una serie de recursos como tierras para el cultivo de pasto, fuerza de trabajo, creatividad y saberes locales. De ninguna manera, los proyectos empresariales y agroindustriales se encuentran ajenos a las experiencias vitales de los hombres y mujeres de comunidades campesinas como Chongos Altos; todo lo contrario, estas comunidades son un colectivo humano con experiencias fundamentales comunes, pero con trayectorias diversas y heterogéneas, con un entramado social y cultural que les permite proyectarse y articularse con estas iniciativas empresariales. De la misma manera ocurre en Ataura y en el Valle del Mantaro, donde las comunidades de su entorno han sido las más dinámicas. Sin embargo, una de las comunidades como Chongos Altos busca tomar el liderazgo de una parte del proceso, productivo, puesto que la empresa "Láctea Andina", pretende después de cinco años, dejar en manos de los mismos comuneros el cuidado de las ovejas, y usufructo de pasto para la obtención de leche de oveja, a fin de constituirse en uno de los principales proveedores de esta empresa y de esa manera encadenarse. El propósito es que las comunidades como chongos y Ataura se conviertan en los principales socios de esta empresa.

Desde una perspectiva histórica, recordemos que el valle del Canipaco es un territorio altoandino y de gran extensión, según Nelson Manrique "en estas tierras históricamente se han enfrentado haciendas y comunidades por el control de los pastos. Haciendas como Laive, Antapongo y Tucle-Río de la Virgen se expandieron sobre tierras comunales y tienen litigios, secularmente arrastrados, con comunidades como Chongos Alto, Chicche o Huasicancha, que han dado lugar, en múltiples ocasiones, a sangrientos enfrentamientos", (Manrique, 1989). Estas comunidades, incluyendo a Chongos Altos se han involucrado en un sin número de luchas desde la Guerra con Chile en el S. XIX, durante y después de ella; luego en la década de 1940, y seguidamente en las masivas movilizaciones de 1962. Pero ya desde la década de 1920, "el enemigo que los comuneros debían enfrentar cambió, pues los hacendados de la región fueron desplazados por fuertes empresas capitalistas controladas por la plutocracia limeña, como la Sociedad Ganadera del Centro (SGC) que llegó a ser propietaria de haciendas como Laive, Antapongo, Tude-Río de la Virgen, situadas en la zona que analizamos, pero también de importantes haciendas ganaderas en la otra margen del Mantaro, como Acopalca, Punto, Huari y Runatullo" (Manrique, 1989). Si bien los hacendados que venían desde el siglo XIX habían sido desplazados por los miembros de la Sociedad Ganadera del Centro, tomando por posesión las haciendas como Laive, reproducían las mismas actitudes que los antiguos hacendados, de prepotencia y ejercicio de violencia simbólica; recordemos que esta sociedad era controlada por la plutocracia limeña (Manrique, 1989).

El gobierno Militar del General Velasco Alvarado impulsó la llegada de la reforma agraria, y se expropiaron las propiedades de la Sociedad Ganadera del Centro, para constituir la "Sociedad Agraria de Interés Social" SAIS-Cahuide, uniendo nueve haciendas (270 122 hectáreas), y 17 de las 63 comunidades ubicadas en su área de influencia. No obstante, la creación de la SAIS no resolvió las demandas centrales de los campesinos, pues aquello que animó por décadas la lucha, fue la restitución a las comunidades de tierras de las que históricamente fueron despojados por las haciendas de la región. (Manrique, 1989). Al respecto Nelson Manrique señala con mucha precisión que "el modelo SAIS dejó sin solucionar la contradicción histórica latifundio-minifundio. En adelante, la contradicción fundamental opondría a los campesinos comuneros con el Estado. A lo largo de las dos

10 Según las fuentes historiográficas. 
últimas décadas, el campesinado continuó desplegando múltiples luchas, con el objetivo de recuperar las tierras en litigio. El grueso de los comuneros juzgaba que la SAIS no los beneficiaba. En más de una oportunidad se llegó a la acción directa, como cuando las comunidades de Chongos Altos, Llamapsillón, Palmáyoc y Palaco se posesionaron de 12000 hectáreas de la Unidad de Producción Antapongo. La asamblea general de socios de la SAIS aprobó por mayoría la reestructuración de la empresa y el 29 de diciembre de 1988 se aprobó la Junta liquidadora" (Manrique, 1989).

En los años más álgidos de violencia, precisamente en 1989, Sendero Luminoso atacó Laive y destruyó por completo la casa hacienda, las instalaciones, los galpones y toda la infraestructura, distribuyendo los enseres de la SAIS y el ganado, el cual fue rematado por precios ínfimos, más de 200 trabajadores fueron obligados a regresar a sus comunidades vecinas; según los datos, las pérdidas fueron cuantiosas: el ganado selecto ascendía a 5000 vacunos y 40000 ovinos; la producción de leche eran de 5000 litros diarios y la de lana de 150 toneladas anuales, y se producía también queso y mantequilla (Manrique.1989). Según la Comisión de la Verdad y Reconciliación (CVR) una de las razones que puede explicar el desencadenamiento de esta masacre, fue el conflicto que existía entre Chongos Altos y Huasicancha, debido a que ambas comunidades disputaban la propiedad de unas 10000 hectáreas de tierras, por lo que algunos sectores -en ausencia de mecanismos eficaces de resolución de conflictos desde el Estadobuscaron resolver el litigio acudiendo a los mandos de la columna senderista, que buscaban presentar sus actos como la mera ejecución de la voluntad de la gente. Ciertamente, cuarenta miembros del PCP-SL asesinaron a doce autoridades comunales de los distritos de Chongos Altos y Chicche. A pesar de todo, las personas que sobrevivieron a la masacre de Sendero Luminoso, se empeñaron en tratar de hacer mejor esta pequeña comunidad. ${ }^{11} Y$ esto se refleja, en el interés que poseen los dirigentes y autoridades locales por construir proyectos de acción colectiva, y apostar - por ejemplo, en este caso, por ser parte del proyecto de Láctea andina y la producción de quesos gourmet- por proyectos en beneficio de la comunidad y sus familias, siempre olvidar los oscuros episodios en la historia de la comunidad.

En el horizonte del desarrollo, los actores comprometidos en esta causa movilizan todos sus saberes y experiencias que han acumulado y vivido durante parte de sus vidas. Ciertamente, la intensa movilidad de los sujetos en los andes, a causa no solo de su participación en los centros mineros o en la economía de mercado dentro de la región, sino también a causa de la migración a ciudades del extranjero. Así, en nuestro trabajo de campo, nos comunicaron que buena parte de los varones de la comunidad viajaron a EE. UU., España, y otros países de Europa; entre las décadas de 1970-2000 han viajado más de 100 comuneros, quienes consiguieron contratos de trabajo en calidad de pastores. Un caso ejemplar lo representa la empresa Western Ranch Association, pues son más de dos mil los campesinos peruanos provenientes de la serranía peruana -específicamente de Chupacas, Junín- quienes fueron captados por esta empresa estadounidense para trabajar en la ganadería de ese país. ${ }^{12}$

11 La comunidad de Chongos, a diferencia de Ataura, se organiza bajo la forma jurídica de comunidad campesina, y de manera similar a Ataura, el espacio de la comunidad se divide en dos barrios, donde cada barrio se subdivide en 3 cuarteles.

12 Un grupo de campesinos peruanos decidió probar suerte en Estados Unidos como borregueros, labor por la que perciben sueldos que oscilan entre 750 y mil 250 dólares mensuales con todos los beneficios sociales, aunque deben tener conocimientos de pastoreo y cumplir ciertas reglas de conducta (http://www.peru.com/ noticias/idocs/2005/10/23/DetalleDocumento_254106.asp). Otra fuente señala la migración de peruanos durante la última década del siglo XX. La gran novedad fue hallar emigrantes de recónditos sectores rurales. El caso de los pastores. Debido al auge lanar, la firma Western Ranch Association contrató hasta 2 mil pastores en Cerro de Pasco. Hoy ellos continúan su solitaria labor en California, Brakesfield, Wasco, Delano, el condado de Tulase y cerca de Lake City (Utah). http://www.elperuano.com.pe/edc/2006/04/12/inf.asp 
Hoy, en Chongos Altos, los residentes fuera del país han regresado convirtiéndose en importantes comerciantes o pequeños empresarios, los mismos que han inyectado dinamismo a la comunidad y han realizado aportes importantes para obras de infraestructura, e incluso se han convertido en autoridades locales; ${ }^{13}$ esto ha sido la oportunidad para utilizar la creatividad, movilizar experiencias de vida, pero, sobre todo, compartir, forjar y promover proyectos colectivos, esto ha sido notablemente reconocido debido al poder simbólico que poseen al interior de la comunidad. Todo este proceso ha permitido que se incorporen nuevos temas dentro de la agenda política de la comunidad de Chongos Altos.

El caso de Chongos Altos es muy importante porque permite explorar cómo se entrelazan las iniciativas locales, los conocimientos adquiridos durante las trayectorias individuales y colectivas, los cuales son re-trabajados de manera creativa, en la búsqueda de escenarios posibles de desarrollo, y que contribuyen a forjar horizontes de sentido sobre el desarrollo local, sin prescindir de la negación, entre los diferentes grupos sociales que poseen intereses particulares. En efecto, el ejercicio de construcción de proyectos colectivos no está exento de la lucha entre visiones parciales, interesadas y hegemónicas subordinadas; sin embargo, los sujetos se empeñan en construir escenarios de negociación, en la cual el discurso hegemónico de la modernización y el discurso de la agroindustria como "salida" a la pobreza, fluye con dinamismo, y se impone como sentido.

Sin embargo, hay que considerar que en todo este proceso existe el fantasma de la SAIS Cahuide y de las antiguas haciendas como Laive, que están en el ambiente. Buena parte de la población posee importantes expectativas sobre la empresa Láctea Andina y las posibilidades de empleo directo. No obstante, parte de la población rechaza tajantemente regresar al modelo de la "SAIS", en el cual solo los burócratas eran los que acumulaban y quienes se beneficiaban, mientras que la mayoría de la población era excluida de la riqueza de estas empresas. La SAIS, a pesar de estimular la creación de empresas comunales que se conviertan en proveedoras lácteas, realizaba pagos a los comuneros muy por debajo de sus expectativas y groseramente desproporcionales a la cantidad de trabajo que realizaban, esto motivó ingresos muy reducidos. Según, la CVR, en este caso hubo una importante desigualdad en la distribución de las tierras, "el panorama se complica cuando revisamos la historia de la creación de la SAIS por la Dirección General de Reforma Agraria y advertimos que hubo en efecto, una desigual distribución de la tierra entre las comunidades campesinas. Las empresas asociativas, junto con las cooperativas agrarias de producción, se beneficiaron con el $75.4 \%$ del total de las tierras intervenidas. De otro lado, solamente el $1.1 \%$ del total fueron entregados a las comunidades campesinas que no eran parte de las empresas asociativas. A consecuencia de este panorama, se suscitan una serie de enfrentamientos entre las comunidades socias y aquellas que quedaron fuera del esquema de la reforma agraria del gobierno militar. De otro lado, la urgencia de las comunidades socias de solicitar la fragmentación de la empresa fue creciendo a lo largo de los años, a diferencia de los funcionarios remunerados de la SAIS que clamaban por la continuidad de la misma. Es de esta manera que en mayo de 1988 se aprueba en asamblea general de socios la «reestructuración» de la empresa".

Como sabemos, esta relación tensa entre la SAIS Cahuide (y en su momento con las haciendas) motivó un intenso conflicto social, que animaba por un lado la lucha por las tierras y por el otro, incrementaba el exacerbado resentimiento a los hacendados, y posteriormente burócratas. Todo esto de alguna manera está presente en la manera de apreciar las cosas entre los comuneros. A pesar de todo, la empresa Láctea Andina despierta estos fantasmas,

13 En este momento, el alcalde viaja constantemente a EE. UU. para mantener su residencia; por otra parte, los residentes en EE. UU. han contribuido a los proyectos de desarrollo en la comunidad. 
la pregunta que nos hacemos, ¿hasta dónde los actores podrán en el futuro cercano lograr consolidar modelos de articulación que permitan que todas las familias que intervienen lo hagan de manera justa y equitativa?

\section{Conclusiones}

Esta exploración nos ha permitido percatarnos de algunos vacíos que son importantes de subrayar, pues complementan el análisis. En ambos casos hay una ausencia de planificación, no se ha desencadenado el llamado proceso de ordenamiento territorial, que permite como herramienta, disponer mejor del territorio, sus recursos y potencialidades; y desde la perspectiva de gestión, permite diseñar mecanismos para que empresas como Láctea Andina u otras desarrollen sus actividades con una visión de sustentabilidad ambiental, social y económica. Afortunadamente en nuestro país están floreciendo los planes de ordenamiento territorial como herramienta en planes de desarrollo regional y local.

Igualmente, hemos comprobado que la contaminación minera está socavando las posibilidades de la pequeña agricultura y muy probablemente a proyectos como Láctea Andina, especialmente en el caso de Ataura, y en menor medida en Chongos Altos. Sin duda, Láctea Andina no ha pensado en la sostenibilidad ambiental, sólo subraya los rentables beneficios económicos, al margen de la importancia en el cuidado del ecosistema y recurso: suelo, agua, pastos naturales, etc.

Por otra parte, los campesinos perciben que los impactos de la minería formal e informal podrían reducir sus oportunidades. Lamentablemente, no existe posibilidad de un eslabonamiento que incremente el impacto de proyectos como los de Láctea Andina, esto sería posible solo si se promueven alternativas para eslabonarse, de otra manera, podría ser muy reducida la participación de la comunidad, si tomamos en consideración que la mayoría de la población que habita permanentemente en estas zonas son personas de edad avanzada. Sin embargo, el escenario podría ser favorable, en la medida que se rehabilite el flujo de mano de obra joven y calificada de la misma comunidad, y que generalmente está asentada en la ciudad de Huancayo.

En nuestra exploración hemos visto cómo el Estado se ha articulado con sus programas a fin de fortalecer estos proyectos como Láctea Andina, incluso la cooperación internacional se ha movilizado. No obstante, no logramos visualizar una acción planificada, y mucho menos concertada, a favor del desarrollo de sociedades rurales, solo vemos acciones concretas que responden a una coyuntura. Láctea Andina significa, sin duda, una importante oportunidad para las comunidades que se articulan; pero, hasta dónde pueden realmente convertirse en oportunidades sostenibles, si en todos los casos, a pesar de todo, el gobierno local es débil y no ha logrado consolidar un enfoque y un aparato de gestión de desarrollo económico local, en el cual los diferentes agentes en la comunidad se convierten en actores locales comprometidos en el bienestar de las familias en las sociedades rurales, desde los emigrantes que envían remesas hasta la empresa Láctea Andina. Hemos constatado una fragmentación que no permite construir un horizonte de desarrollo. Esto no significa menos precisar el rol de los migrantes que invierten en la comunidad. Pero el problema es que su participación es coyuntural.

A partir de nuestro caso, podemos afirmar que la agroindustria está empotrado en las estructuras cognitivas, en esquemas mentales, en sus expectativas, y en su historia; todos estos elementos fundan el universo de lo posible, que al mismo tiempo dialoga, con luchas al interior de la comunidad, y entre comunidades. La propuesta de quesos gourmet para el mercado norteamericano, la industria de la alcachofa, entre otros productos, se ha incorporado en el universo de lo posible de los campesinos. En la actualidad han asumido 
la existencia de una ola de demandas de productos que generalmente no eran consumidos por el mercado local y regional. Todo esto ha permitido pensar en nuevas posibilidades de comercio e intercambio en mercados internacionales, muchos campesinos admiten con asombro cómo varios productos (tanto nativos como foráneos) son parte de la dieta de otros países.

La acción de la demanda internacional, la emergencia de mercados, y el interés de empresarios locales por articularse con estos mercados y oportunidades de comercio, está transformando la visión que tienen los campesinos y pastores sobre el mundo de los alimentos y comidas; puesto que el mundo de los alimentos y la comida reposa en las propias prácticas culturales y sociales asociadas a sus propios productos históricamente definidos y que posteriormente fueron puestos en economías de mercados, tanto en el ámbito regional como local. 